\title{
Knowledge, Attitudes and Behaviors of University Students Regarding the Harassment on Social Media in Turkey
}

\author{
Oğuz POLAT ${ }^{1}$, Zeynep REVA ${ }^{2^{*}}$ \\ ${ }^{\text {I}}$ Professor, M.D. Acıbadem Mehmet Ali Aydinlar University, Faculty of Medicine, Department of Forensic \\ Medicine. İstanbul, Turkey. \\ ${ }^{2}$ LL.M. / Ph.D. (c), Istanbul Medeniyet University, Department of Medical Law, İstanbul, Turkey.
}

*Corresponding Author: Zeynep REVA, LL.M. / Ph.D.(c), İstanbul Medeniyet University, Department of Medical Law, Istanbul, Turkey.

\begin{abstract}
Harassment on social media (SM) is a well-known social problem that affects university students. This study aims to examine the knowledge and behaviors of university students on actions and subject of harassment on SM. 507 university students from Istanbul/Turkey had valid answers to the survey and the answers were analysis based. The study found that females were nearly two times more likely to be subjected to a sexual expression on SM than males. Nearly half of the participants indicated that they had experienced differing types of harassment on SM. There were significant correlations between ever being subjected to any sexual expression on SM and gender, time spent on SM, other purposes. SM harassment among university students is a serious problem. Being aware of their knowledge, behaviors, gender differences and various predictors regarding harassment on SM may help to generate practical policies for universities, parents, other authorities to mitigate negative effect.
\end{abstract}

Keywords: Harassment; social media; sexual expression; victimization; cyber bullying; cyber victimization; sexual harassment.

\section{INTRODUCTION}

Social media platforms are an effective platform for online harassment and that over 2016 internet usage rates indicate that over 3.4 billion people are connected internets and 2.3 billion of them are actively using social media. There are over 46 million people in Turkey who have internet connection and 42 million people actively spend time in social media. High rates of exploitation of the majority of harassment incidents take place in the social media. Research has shown that cyber bullies usually target personal or physical characteristics. (xTRlarge, 2017) (OHR17, 2017)

Social Media(SM) is widely used for meeting new people and sharing information, news, private materials with friends as pleasure/fun, having boyfriend/girlfriend and to express oneself. In a study the SM using purposes are grouped under four categories, namely maintaining existing relationships, constructing new relationships, using for academic purposes and following specific agenda (Mazman \& Usluel, 2011)

Online harassment may include threatening, worrisome, emotionally hurtful or sexual messages delivered via an electronic medium that can lead victims to feel fear or distress like real-world harassment and stalking (Bossler et al., 2012). Sengupta and Chaudhuri, 2011, mentioned that females were 2.4 times more likely to be harassed on internet than males.

In a study in Turkey, they found that females were especially disturbed on SM due to their gender and females had a higher mean than males in online potential harassment acts of misogyny, request for company and sexual favors regarding to the university students' opinion(Turan et al., 2011),(Biber et al., 2002)

\subsection{Research Problem and Aim of the Study}

Social media has become "a vector for youth violence," (Patton et al., 2014) Social media has produced new forms of aggression and violence that occur exclusively online.

According to Population Association Report, the total population of Turkey is approximately 82 million and the rate of the population of $15-24$ aged is $15,82 \%$ and $15.58 \%$ of it is female (Turkstat, Population Report, 2019). Turkey has the youngest population in Europe. 
Knowledge, Attitudes and Behaviors of University Students Regarding the Harassment on Social Media in Turkey

According to the research made by Wearesocial.Net; internet user rate is $59.5 \%$ worldwide while this rate is $77.7 \%$ in Turkey; social media user rate is $53.6 \%$ worldwide, while this rate is $70.8 \%$ in Turkey. An average of 2 hours and 57 minutes a day is spent on social media. 50.6 million people use Youtube, 46 million people use Instagram, 38 million people use Facebook, 13.6 million people use twitter, 11.1 million people use snapchat, and 9.8 million people use LinkedIn in Turkey. The social media usage in Turkey is higher than the average usage worldwide. (We are Social - Global, 2021; We are Social - Turkey, 2021) (Figure 1)

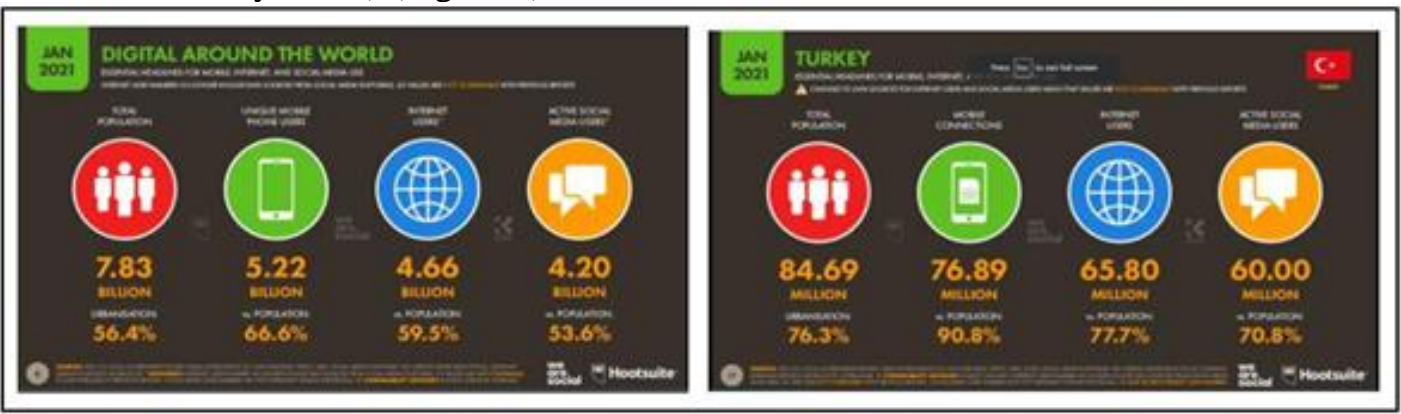

Figure1. Digital Usage around the Worldwide \& in Turkey

This study aims to put the current situation in numbers as the first step of preventing the harassment on social media and to examine the knowledge, attitudes and behaviors of university students related to the harassment on SM regarding to the various attitudes and demographic variables.

\section{Method}

\subsection{Participants}

This research is based on descriptive research model. The target population consists of university students from Medicine, Law and school of Psychology. Consequently, analysis basis for the participants of this study were 507 university students including 337 females (66.5\%) and 170 males (33.5\%) from three different faculty departments as Law (28.6\%), Medicine (37.9\%) and Psychology (33.5\%) from different universities located Istanbul, Turkey. They were aged between 18-23 (64.3\%) and 24+ years old (35.7\%). Almost all of them were using smart phones $(99.4 \%)$. Furthermore, majority of the participants (68.8\%) were spending between 1 to 5 hours on internet and between 1 to 3 hours on SM daily (42.8\%). Instagram (84.6\%) was the most frequently used SM platform among the university students followed by Twitter (51.5\%), Snapchat (49.7\%) and Facebook (44.0\%).

Table1. Participants characteristics

\begin{tabular}{|l|l|l|l|}
\hline & Frequency & Percentage (\%) & Cumulative Percent (\%) \\
\hline Gender & & & \\
\hline Female & 337 & 66.5 & 66.5 \\
\hline Male & 170 & 33.5 & 100.0 \\
\hline Age & & & \\
\hline $18-23$ years & 326 & 64.3 & 64.3 \\
\hline 24+ years & 181 & 35.7 & 100.0 \\
\hline Faculty Department & & & \\
\hline Law & 145 & 28.6 & 28.6 \\
\hline Medicine & 192 & 37.9 & 66.5 \\
\hline Psychology & 170 & 33.5 & 100.0 \\
\hline Do you use smart phone? & & & \\
\hline No & 3 & 0.6 & 0.6 \\
\hline Yes & 504 & 99.4 & 100.0 \\
\hline Time spent on internet daily? & & & \\
\hline Less than 1 hour & 40 & 7.9 & 7.9 \\
\hline 1 to 3 hours & 174 & 34.3 & 42.2 \\
\hline 3 to 5 hours & 175 & 34.5 & 76.7 \\
\hline More than 5 hours & 118 & 23.3 & 100.0 \\
\hline Time spent on Social Media (SM) daily? & & & \\
\hline Less than 1 hour & 120 & 23.7 & 23.7 \\
\hline
\end{tabular}


Knowledge, Attitudes and Behaviors of University Students Regarding the Harassment on Social Media in Turkey

\begin{tabular}{|l|l|l|l|}
\hline 1 to 3 hours & 217 & 42.8 & 66.5 \\
\hline 3 to 5 hours & 116 & 22.9 & 89.3 \\
\hline More than 5 hours & 54 & 10.7 & 100.0 \\
\hline Which SM platform do you use? & & & \\
\hline Facebook & 222 & 44.0 & \\
\hline Instagram & 427 & 84.6 & \\
\hline Twitter & 260 & 51.5 & \\
\hline Snapchat & 251 & 49.7 & \\
\hline Sour Dictionary & 115 & 22.8 & \\
\hline Other SM Dictionary & 21 & 4.2 & \\
\hline Other & 81 & 16.0 & \\
\hline
\end{tabular}

\subsection{Procedure}

The respondents participated to the survey voluntarily. It has been applied to the Ethical Committee of Acibadem Mehmet Ali Aydinlar University for the survey / field study and the ethical approval has been obtained. The outcomes of this survey have been statistically analyzed by SPSS Statistics 20 .

\subsection{Measures}

In this study, all terms are used to indicate some sort of aggressive behaviors faced on SM platforms. In this context, sexual expression is used as a discourse in SM to be perceived by the victim as sexual pressure, sexual coercion, online grooming, unwanted exposure to sexual content or violation of privacy (Montiel et al, 2016). The term harassment on SM is used to mean in a broader sense as an online harassment which consist of threatening, worrisome, emotionally hurtful, or sexual messages delivered via an electronic medium that can lead victims to feel fear or distress much like real-world harassment and stalking (Bossler et al., 2012).

The survey questionnaire consisted of two sections. The first set of questions (number of 11) were categorical variables about demographics and characteristics of the participants such as gender, age, faculty department, smart phone usage, time spent on SM daily and the SM usage purposes. The second set of questions (number of 27) were categorical variables about the knowledge, attitudes, and behaviors of university students regarding the social media harassment in Turkey.

In the analysis, SPSS Statistics 20 were used.

\section{Dependent Variable}

The dependent variable of the study is the likelihood of being subjected to any sexual expression on SM. This variable was questioned in the survey as "Have you ever been subjected to any sexual expression in SM?". The dependent variable was a dichotomous variable coded as $0=$ no, $1=$ yes.

\section{Independent Variables}

The gender was a dichotomous variable ( $0=$ female, $1=$ male).

The relationship between categorical variables and the knowledge, attitudes, and behaviors of university students regarding the harassment on social media were analyzed by dummy variables coded as $0=$ no, $1=$ yes and with chi-square analysis. Yates' correction for continuity values with corresponding $p$ values were used to check significance of the associations.

There were survey questions which were allowed with multiple answers to be marked. Each selection was dummy coded with $1=$ marked, $0=$ not marked. In multiple answer questions, Bonferroni corrected $p$ values are used to check significance.

Direct logistic regression was performed to assess the impact of a number of various attitudes, gender and the likelihood that participants would report ever being subjected to any sexual expression on SM. Dichotomous variables coded $(0=$ not-marked/no, $1=$ marked/yes $)$. Ordinal variables were coded with dummy variables with last level as being the reference.

\section{Results}

\subsection{The Associations between Gender and Knowledge, Attitudes and Behaviors of University Students Regarding the Harassment on SM}

The purpose of SM usage among university students were investigated by asking them "For what purpose do you use SM?" question. The most frequent two selections were sharing with friends 
Knowledge, Attitudes and Behaviors of University Students Regarding the Harassment on Social Media in Turkey

(72.9\%) and pleasure/fun (71.9\%) and the least frequent one was having boyfriend/girlfriend(6.3\%). There was a significant difference between the genders; $78.9 \%$ of females and $60.9 \%$ of males were using SM for sharing with friends, $\square[2(1, N=506)=17.54, p<.001, p h i=-.191$. The females were nearly 2.5 times more likely to use SM for sharing with friends than males $(O R=2.40)$. On the other hand, males (18.9\% and $13 \%)$ were more likely to use SM for meeting with new people $\square 2(1, N=506)$ $=7.00, p<.01, p h i=.124$, OR=2.08 and for having boyfriend/girlfriend $\square 2(1, N=506)=17.53, p<.001$, $p h i=.195$, OR=4.90 than females $(10.1 \%$ and $3.0 \%)$.

When inspecting the association of reporting being subjected to any sexual expression on SM, a significant difference was detected between females (52.2\%) and males $(38.2 \%), \square \square 2(1, N=507)$ $=8.32, p<.001, p h i=-.132$. Based on the odds ratio, females were nearly 2 times more likely to be subjected to a sexual expression on SM than males $(O R=1.77)$.

Familiarity with the harasser was asked to participants. The most frequent answer was an unknown person $(89.0 \%)$ and the least frequent two replies were girl/boy friend or spouse (1.6\%) and family member $(2.0 \%)$.

When questioning the type of the harassment on SM, among females, the most frequent answer was stalking (52.6\%) and the least frequent one was physical menace (4.6\%), whereas among males the most frequent answer was mock or curse (61.6\%) and the least frequent one was sexual harassment $(19.2 \%)$.

Participants feelings were asked and the most frequent answer was feeling anger (76.7\%) and the least frequent was having pleasure (2.1\%).There was a significant difference between the harassed participants genders; females $(81.3 \%$ and $25.8 \%)$ were more likely to feel anger when experienced a SM harassment, $\square \square(1, N=288)=8.13, p<.01, p h i=-.177, O R=2.39$ and ashamed $\square 2(1, N=288)$ $=10.49, p<.01$, phi $=-.200, O R=4.24$ than males $(64.6 \%$ and $7.6 \%)$; whilst males $(48.1 \%$ and $6.9 \%)$ were more likely to feel indifference $\square 2(1, N=288)=16.11, p<.001, p h i=-.245$, OR=4.08and have pleasure, Fisher's exact test, $p<.01$, phi $=.208, O R=30.93$ than females $(23.0 \%$ and $0.2 \%)$.

Table 2 shows the data analysis results in detail for the significant associations between gender and knowledge, attitudes and behaviors of university students regarding the harassment on SM characteristics. The non significant ones are also shown in Table 2

Table2. The significant associations between gender and knowledge, attitudes and behaviors of university students regarding the harassment on SM characteristics

\begin{tabular}{|c|c|c|c|c|c|c|c|c|c|c|c|c|c|c|}
\hline & \multicolumn{3}{|c|}{ Valid Total } & \multicolumn{2}{|c|}{ Female } & \multicolumn{2}{|c|}{ Male } & \multirow[t]{2}{*}{2} & \multicolumn{2}{|c|}{$d f \quad p$} & \multicolumn{3}{|c|}{\begin{tabular}{l|l}
$O R$ & $\% 95 \mathrm{CI}$
\end{tabular}} & \multirow[t]{2}{*}{ phi } \\
\hline & Cases & & $\%$ & $n$ & $\%$ & $\hbar$ & $\%$ & & & & $\mathrm{~F} / \mathrm{M}$ & Lower & Upper & \\
\hline \begin{tabular}{|l} 
For what purpose \\
do \\
you \\
\end{tabular} & 506 & & & & & & & & & & & & & \\
\hline $\begin{array}{l}\text { a) Sharing with } \\
\text { friends } \\
\end{array}$ & & 369 & $72.9 \%$ & 266 & $78.9 \%$ & 103 & $60.9 \%$ & 17.541 & & $.000 *$ & 2.40 & 1.601 & 3.599 & 191 \\
\hline $\begin{array}{l}\text { b) Meeting with } \\
\text { new people }\end{array}$ & & 66 & $13.0 \%$ & 34 & $10.1 \%$ & 32 & $18.9 \%$ & 7.001 & & $.008 *$ & 0.48 & 0.285 & 0.811 & 124 \\
\hline c) Pleasure/Fun & & 364 & $71.9 \%$ & 249 & $73.9 \%$ & 115 & $68.0 \%$ & 1.621 & & 203 & 1.33 & 0.887 & 1.991 & 061 \\
\hline \begin{tabular}{|l|} 
d) Having \\
boyfriend/girlfriend
\end{tabular} & & 32 & $6.3 \%$ & 10 & $3.0 \%$ & 22 & $13.0 \%$ & 17.531 & & $.000 *$ & 0.20 & 0.094 & 0.442 & 195 \\
\hline $\begin{array}{l}\text { e) To express } \\
\text { myself }\end{array}$ & & 119 & $23.5 \%$ & 88 & $26.1 \%$ & 31 & $18.3 \%$ & 3.361 & & .067 & 1.57 & 0.994 & 2.490 & 086 \\
\hline $\begin{array}{l}\text { Have you ever been } \\
\text { subjected to any } \\
\text { sexual } \\
\text { expression in SM? }\end{array}$ & 507 & 241 & $47.5 \%$ & 176 & $52.2 \%$ & 65 & $38.2 \%$ & 8.32 & 1 & $.004 *$ & 1.77 & 1.212 & 2.572 & 132 \\
\hline $\begin{array}{l}\text { Who was the } \\
\text { harasser } \\
\text { on SM? }\end{array}$ & 500 & & & & & & & & & & & & & \\
\hline a) Friend & & 40 & $16.3 \%$ & 22 & $12.3 \%$ & 18 & $26.9 \%$ & 6.57 & 1 & 010 & 0.38 & 0.189 & 0.769 & 176 \\
\hline
\end{tabular}


Knowledge, Attitudes and Behaviors of University Students Regarding the Harassment on Social Media in Turkey

\begin{tabular}{|c|c|c|c|c|c|c|c|c|c|c|c|c|c|c|c|}
\hline $\begin{array}{l}\text { b) Girl/boy friend } \\
\text { or spouse }\end{array}$ & & 4 & $1.6 \%$ & & $1.1 \%$ & 2 & $3.0 \%$ & $0.22 \mid 1$ & & 299 & & 0.37 & 0.051 & 2.661 & 066 \\
\hline c) Ex girl/boy & & 14 & $5.7 \%$ & 10 & $5.6 \%$ & 4 & $6.0 \%$ & 0.00 & 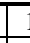 & $\# \# \# \#_{\mathrm{b}}$ & & 0.93 & 0.282 & 3.079 & .007 \\
\hline \multicolumn{16}{|l|}{ friend or spouse } \\
\hline d) Family Member & & 5 & $2.0 \%$ & 2 & $1.1 \%$ & 3 & $4.5 \%$ & 0.13 & 1 & $.338 \mathrm{~b}$ & & 0.24 & 0.039 & 1.476 & 106 \\
\hline e) An unknown & & 219 & $89.0 \%$ & 166 & 92.7\% & 53 & 79.1\% & \begin{tabular}{l|l|l}
7.93 \\
\end{tabular} & 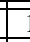 & 2.005 * & & 3.37 & 1.492 & 7.626 & \\
\hline person & & & & & & & & & & & & & & & .194 \\
\hline f) I have not been & & 253 & $50.6 \%$ & 156 & $46.6 \%$ & 97 & $58.8 \%$ & 6.13 & . & .013 & & 0.61 & 0.419 & 0.891 & .115 \\
\hline \multicolumn{16}{|l|}{ harassed } \\
\hline What was the type of & 507 & & & & & & & & & & & & & & \\
\hline \multicolumn{16}{|l|}{$\begin{array}{l}\text { the harassment on SM? } \\
\mathrm{BC}, \mathrm{a} \\
\end{array}$} \\
\hline a) Physical menace & & 28 & $10.5 \%$ & 9 & $4.6 \%$ & 19 & $26.0 \%$ & 23.621 & & $.000 *$ & & 0.14 & \begin{tabular}{|l|}
0.059 \\
\end{tabular} & 0.323 & 311 \\
\hline b) Humiliating & & 60 & $22.5 \%$ & 41 & $21.1 \%$ & 19 & \multicolumn{2}{|c|}{$2 \frac{1}{26.0 \% 0.48}$} & & .491 & & 0.76 & 0.407 & 1.425 & \begin{tabular}{|c|}
.052 \\
\end{tabular} \\
\hline nickname & & & & & & & & & & & & & & & \\
\hline c) Stalking & & 127 & $47.6 \%$ & 102 & $52.6 \%$ & 25 & & $2 \% 6.43$ & & .011 & & 2.13 & 1.216 & 3.725 & \\
\hline & & & & & & & & & & & & & & & .164 \\
\hline d) Sexual & & 101 & $37.8 \%$ & 87 & $44.8 \%$ & 14 & 19. & $2 \% 13.79$ & & $.000 *$ & & 3.43 & 1.793 & 6.549 & \\
\hline harassment & & & & & & & & & & & & & & & 236 \\
\hline e) Mock or curse & & 114 & $42.7 \%$ & 69 & $35.6 \%$ & 45 & 61. & $\left.6 \% 13.70\right|_{1}$ & & $.000 *$ & & 0.34 & $|0.197|$ & 0.599 & 235 \\
\hline f) I have not been & & 235 & $46.4 \%$ & 142 & $42.1 \%$ & 93 & 54. & $7 \% 6.68$ & & .010 & & 0.60 & 0.094 & 0.480 & .119 \\
\hline harassed & & & & & & & & & & & & & & & \\
\hline What do you think the & 485 & & & & & & & & & & & & & & \\
\hline reason was for the SM & & & & & & & & & & & & & & & \\
\hline harassment? ${ }^{\mathrm{BC}, \mathrm{a}}$ & & & & & & & & & & & & & & & \\
\hline a) Physical & & 111 & $43.0 \%$ & 93 & $48.9 \%$ & 18 & $26.5 \%$ & 9.421 & & $.002 *$ & & 2.66 & 1.448 & 4.898 & \\
\hline appearance & & & & & & & & & & & & & & & 200 \\
\hline b) Gender or & & 152 & $58.9 \%$ & 134 & $70.5 \%$ & 18 & $26.5 \%$ & 38.361 & & $.000 *$ & & 6.65 & 3.567 & 12.387 & \\
\hline sexual harassment & & & & & & & & & & & & & & & 395 \\
\hline c) Political opinion & & 77 & $29.8 \%$ & 39 & $20.5 \%$ & 38 & & $9 \% 28.23$ & & $.000 *$ & & 0.34 & 0.113 & 0.369 & 340 \\
\hline d) Race & & 32 & $12.4 \%$ & 13 & $6.8 \%$ & 19 & & $.9 \% 18.62$ & & $.000 *$ & & 0.19 & \begin{tabular}{|l|}
0.087 \\
\end{tabular} & 0.410 & 282 \\
\hline e) I have not been & & 226 & $46.6 \%$ & 136 & $41.7 \%$ & 90 & & $6 \% 8.93$ & & $.003 *$ & & 0.55 & \begin{tabular}{|l|}
0.374 \\
\end{tabular} & 0.805 & 140 \\
\hline harassed & & & & & & & & & & & & & & & \\
\hline How would you & 498 & & & & & & & & & & & & & & \\
\hline describe your feelings & & & & & & & & & & & & & & & \\
\hline when you were & & & & & & & & & & & & & & & \\
\hline subjected to harassment & & & & & & & & & & & & & & & \\
\hline on SM? ${ }^{\mathrm{BC}, \mathrm{a}}$ & & & & & & & & & & & & & & & \\
\hline a) Anger & & 221 & $76.7 \%$ & 170 & $81.3 \%$ & 51 & $64.6 \%$ & 8.13 & 7 & $.004 *$ & & 2.39 & 1.343 & 4.264 & \\
\hline & & & & & & & & & & & & & & & 177 \\
\hline b) Shame & & 60 & $20.8 \%$ & 54 & $25.8 \%$ & 6 & $7.6 \%$ & 10.49 & 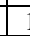 & $.001 *$ & & 4.24 & $\mid 1.744$ & 10.303 & \\
\hline & & & & & & & & & & & & & & & 200 \\
\hline c) Indifference & & 86 & $29.9 \%$ & 48 & $23.0 \%$ & 38 & $48.1 \%$ & 16.11 & 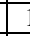 & $.000 *$ & & 0.25 & 0.186 & 0.556 & 245 \\
\hline d) Fear & & 69 & $24.0 \%$ & 57 & $27.3 \%$ & 12 & $15.2 \%$ & 3.95 & $=$ & $\mid 047$ & & 2.09 & 1.055 & 4.156 & \\
\hline & & & & & & & & & & & & & & & .126 \\
\hline e) Guilt & & 15 & $5.2 \%$ & 14.5 & $6.9 \%$ & 0.5 & $0.6 \%$ & 3.47 & 1 & $.063 \mathrm{~d}$ & & 11.79 & 0.695 & 200.08 & \\
\hline & & & & & & & & & & & & & & & 127 \\
\hline f) Pleasure & & 6 & $2.1 \%$ & 0.5 & $0.2 \%$ & 5.5 & $6.9 \%$ & 9.53 & 1 & $.002 *$ &, $\mathrm{~b}$, & 0.03 & 0.002 & 0.592 & .208 \\
\hline & & & & & & & & & & & & 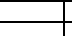 & & & \\
\hline g) I have not been & & 210 & $42.2 \%$ & 126 & $37.6 \%$ & 84 & $51.5 \%$ & 8.15 & 1 & $.004 *$ & & 0.57 & 0.388 & 0.828 & .132 \\
\hline harassed & & & & & & & & & & & & & & & \\
\hline Do you believe that & 491 & 268 & $54.6 \%$ & 158 & $47.9 \%$ & 110 & $68.3 \%$ & 17.43 & 1 & $.000 *$ & & 0.43 & \begin{tabular}{|l|}
0.287 \\
\end{tabular} & 0.633 & 193 \\
\hline your girl/boyfriend has & & & & & & & & & & & & & & & \\
\hline a right to stalk your SM & & & & & & & & & & & & & & & \\
\hline accounts? & & & & & & & & & & & & & & & \\
\hline Did you delete a friend & 485 & 186 & $38.4 \%$ & 122 & $37.7 \%$ & 64 & $39.8 \%$ & 0.12 & 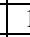 & .728 & & 0.92 & 0.621 & 1.349 & 020 \\
\hline with opposite gender & & & & & & & & & & & & & & & \\
\hline from your SM account & & & & & & & & & & & & & & & \\
\hline due to your & & & & & & & & & & & & & & & \\
\hline boy/girlfriend's & & & & & & & & & & & & & & & \\
\hline reaction? & & & & & & & & & & & & & & & \\
\hline If yes, how & 176 & 176 & $100.0 \%$ & 114 & $64.8 \%$ & 62 & $35.2 \%$ & 8.71 & 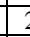 & $.013 *$ & & & & & \\
\hline uncomfortable did you & & & & & & & & & & & & & & & \\
\hline feel due to his/her & & & & & & & & & & & & & & & \\
\hline reaction? & & & & & & & & & & & & & & & \\
\hline a) Too & & 54 & $30.7 \%$ & 40 & $35.1 \%$ & 14 & $22.6 \%$ & & & & & & & & \\
\hline annoying, destroyed my & & & & & & & & & & & & & & & \\
\hline relationship & & & & & & & & & & & & & & & \\
\hline b) Annoyed & & 99 & $56.3 \%$ & 65 & $57.0 \%$ & 34 & $54.8 \%$ & & & & & & & & \\
\hline but did not react to & & & & & & & & & & & & & & & \\
\hline protect my relationship & & & & & & & & & & & & & & & \\
\hline c) Liked it, & & 23 & $13.1 \%$ & 9 & $7.9 \%$ & 14 & $22.6 \%$ & & & & & & & & \\
\hline since it was & & & & & & & & & & & & & & & \\
\hline demonstration of his/her & & & & & & & & & & & & & & & \\
\hline love to me & & & & & & & & & & & & & & & \\
\hline Notes: & & & & & & & & & & & & & & & \\
\hline${ }^{a}$ Multiple responses can & $\mathrm{ema}$ & $\mathrm{d},{ }^{\mathrm{D}} \mathrm{Fi}$ & exact t & Pea & on $\mathrm{Ch}$ & are, & & & & e cror & & & ign & alue, & \\
\hline
\end{tabular}


Knowledge, Attitudes and Behaviors of University Students Regarding the Harassment on Social Media in Turkey

OR Odds ratio, $C I$ Confidence interval, $d f$ Degrees of freedom, $n$ Number of positive responses, $p h i$ Correlation coefficient, $c^{2}$ Chi-square with Yates' correction for continuity, BC p values checked against Bonferroni corrected values for significance, F Female, M Male

\subsection{The Association between and the Type of Harassment faced and SM usage Purpose}

The associations between the type of harassment faced and SM usage purpose were analyzed using multiple marginal independence test. Aggregated data are shown in Table 3. Each data herein shows positive responses by total of 460 valid cases. By following Agresti and Lui (1999), one can create $5 \times 6=302 \times 2$ marginal tables and sums up to Pearson $\square \square 2(30, N=460)=143.89, p<.001$. Therefore, the association is significant. As a follow-up analysis, odds ratios were calculated to find out the strongest associations. Based on that, the strongest associations were found between "meeting new people", "pleasure/fun", "having boyfriend/girlfriend" and "physical menace" (OR=6.30, OR=3.91 and $\mathrm{OR}=3.49$ ).

Table3. Contingency table with multiple positive responses

\begin{tabular}{|c|c|c|c|c|c|c|c|}
\hline For what purpose do & \multicolumn{6}{|c|}{ What was the type of the harassment you faced on SM? } & \\
\hline & Physical & Humiliating & Stalking & Sexual & Mock & I have & Total \\
\hline & menace & nickname & & harassment & or & not been & "Marked" \\
\hline & & & & & curse & harassed & in rows \\
\hline Sharing with friends & 16 & 49 & 104 & 85 & 91 & 159 & 364 \\
\hline Meeting new people & 12 & 9 & 18 & 16 & 19 & 21 & 64 \\
\hline Pleasure/Fun & 20 & 49 & 101 & 81 & 79 & 167 & 358 \\
\hline Having & 5 & 7 & 8 & 4 & 12 & 12 & 32 \\
\hline boyfriend/girlfriend & & & & & & & \\
\hline To express myself & 8 & 23 & 44 & 33 & 39 & 31 & 117 \\
\hline Total "Marked" in & 26 & 57 & 119 & 96 & 109 & 213 & \\
\hline columns & & & & & & & \\
\hline
\end{tabular}

\subsection{The Correlation between ever being Subjected to any Sexual Expression on SM and Various Attitudes and Demographic Variables}

Table 6 shows the correlation coefficients between ever being subjected to any sexual expression on SM and various attitudes and demographic variables. Results showed that there was significant correlation between gender and being subjected to any sexual expression in SM ( $p h i=.-132, p<.01)$. In addition, there was significant correlation between time spent on SM and being subjected to any sexual expression on SM $(r=.101, p<.05)$. Among the SM usage attitudes of the participants, sharing with friends $(p h i=.136, \mathrm{p}<.01)$, meeting new people $(p h i=.112, p<.05)$, to express myself $(p h i=$ $.208, p<.001$ ) were significantly associated with being subjected to any sexual expression on SM.

No significant correlation between age, SM usage attitudes pleasure/fun, having boyfriend/girlfriend and being subjected to any sexual expression on SM have been found.

\subsection{The Impact of Various Predictor Attitudes and Gender on ever being Subjected to any Sexual Expression on SM}

As summarized in Table 4, the full model containing all predictors was statistically significant $\square \square 2$ $(10, \mathrm{~N}=504)=41.90, \mathrm{p}<.001$, hence the model was able to distinguish between participants who reported and did not report themselves ever having any sexual expression on SM. The model as a whole correctly classified $62.9 \%$ of cases. Only two of the independent variables (gender and to express myself) made a unique statistically significant contribution to the model. The strongest categorical predictor variable which predicted ever subjected to any sexual expression on SM was to express myself with an odds ratio of 2.12, $p<.001$. This indicated that participants who were using SM to express themselves were nearly 2 times more likely to confront sexual expression on SM than those who were not, controlling for all other factors in the model. The gender as a predictor was with an odds ratio of $1.66, \mathrm{p}<.05$. This indicated that females were nearly 1.5 times more likely to confront sexual expression on SM than males, controlling for all other factors in the model. Additionally, participants who certainly considered SM as a communication platform to express themselves in any subject even radically were more likely to report SM sexual expression experiencing than who did not think so with an odds ratio of $2.33, \mathrm{p}<.05$, controlling for all other factors in the model. 
Knowledge, Attitudes and Behaviors of University Students Regarding the Harassment on Social Media in Turkey

Table4. Various attitudes and gender logistic regression predicting likelihood of ever being subjected to any sexual expression in $S M$

\begin{tabular}{|l|l|l|l|l|l|l|l|l|}
\hline & B & S.E. & Wald & df & Sig. & \multicolumn{2}{|l|}{ Odds } & \multicolumn{2}{|l|}{ 95\% C.I. } \\
\hline & & & & & & Ratio & & \\
\hline & & & & & & & Lower & Upper \\
\hline Gender (Female) & 0.51 & 0.21 & 5.78 & 1 & .016 & 1.66 & 1.098 & 2.513 \\
\hline Sharing with friends & 0.32 & 0.22 & 2.05 & 1 & .153 & 1.38 & 0.888 & 2.138 \\
\hline Meeting new people & 0.47 & 0.30 & 2.46 & 1 & .117 & 1.61 & 0.888 & 2.909 \\
\hline To express myself & 0.75 & 0.23 & 10.35 & 1 & .001 & 2.12 & 1.340 & 3.344 \\
\hline Time spent in SM daily & & & 1.69 & 3 & .638 & & & \\
\hline 3 to 5 hours & -0.28 & 0.37 & 0.58 & 1 & .447 & 0.76 & 0.369 & 1.553 \\
\hline 1 to 3 hours & -0.10 & 0.33 & 0.10 & 1 & .752 & 0.90 & 0.476 & 1.711 \\
\hline Less than 1 hour & -0.35 & 0.35 & 1.01 & 1 & .314 & 0.70 & 0.355 & 1.395 \\
\hline Do you consider SM as a communication & & & 5.59 & 3 & .133 & & & \\
\hline platform to express yourself in any subject & & & & & & & & \\
\hline even radically? & & & & & & & & \\
\hline Yes, I think so & -0.65 & 0.45 & 2.06 & 1 & .151 & 0.52 & 0.215 & 1.268 \\
\hline No, I don't think so & -0.84 & 0.36 & 5.52 & 1 & .019 & 0.43 & 0.216 & 0.871 \\
\hline No, I certainly don't think so & -0.61 & 0.34 & 3.17 & 1 & .075 & 0.55 & 0.280 & 1.062 \\
\hline Constant & -0.09 & 0.49 & 0.03 & 1 & .856 & 0.92 & & \\
\hline
\end{tabular}

Note: .06 (Hosmer \&Lemeshow), .08 (Cox \& Snell), .11 (Nagelkerke). Model $-2 L L=655.65, \chi 2(10, N=504)=$ 41.90, $p<.001$.

\subsection{School Department and Freedom of Expression Perception on SM}

To understand the relations between school department and freedom of expression perception on SM, respondents from three different school departments (Law, Medicine and Psychology) were asked with "Do you defend freedom of expression that internet/SM provides despite potential insult or harassment?".The chi-square test indicated that the difference in departments was significant; Pearson $\chi 2(2, \mathrm{~N}=506)=18.36, p<.001$. The frequencies of replies to this question are shown incontingency Table 5 .

Table5. Contingencies between school major and freedom of expression supportiveness on SM

\begin{tabular}{|c|c|c|c|c|}
\hline & \multicolumn{2}{|r|}{ No } & \multicolumn{2}{|r|}{ Yes } \\
\hline $\begin{array}{l}\text { Do you defend freedom of expression that internet/SM } \\
\text { provides despite potential insult or harassment? }\end{array}$ & $\mathrm{n}$ & $\%$ & $\mathrm{n}$ & $\%$ \\
\hline Law Department & 71 & $26.3 \%$ & 73 & $30.9 \%$ \\
\hline Medicine Department & 86 & $31.9 \%$ & 106 & $44.9 \%$ \\
\hline Psychology Department & 113 & $41.9 \%$ & 57 & $24.2 \%$ \\
\hline
\end{tabular}

Note: Pearson $\square \square(2, N=506)=18.36, p<.001$

Direct logistic regression was performed to assess the impact of the school department and the likelihood that participants would report to defend freedom of expression that internet/SM provides despite potential insult or harassment. In the analysis, as a dependent variable 236 (46.6\%) "yes" and $270(53.4 \%)$ "no" responses were used.

The model composed of one dependent variable "Do you defend freedom of expression that internet/SM provides despite potential insult or harassment?" (no=0, yes $=1$ ) and an independent categorical variable school department (Law=0, Medicine=1, Psychology =2) coded with dummy variables with last level as being the reference.

As summarized in Table 9, the model was statistically significant $\square \square 2(2, \mathrm{~N}=506)=18.62, p<.001$. The model correctly classified $57.7 \%$ of cases. Both independent variables made a unique statistically significant contribution to the model (law and medicine departments). Students of Law department were nearly 2 times and Medicine department were nearly 2.5 times more likely to defend freedom of expression that internet/SM provides despite potential insult or harassment than Psychology department. The detailed analysis results are shown in Table 6 
Knowledge, Attitudes and Behaviors of University Students Regarding the Harassment on Social Media in Turkey

Table6. School department logistic regression predicting likelihood of freedom of expression supportiveness in $S M$

\begin{tabular}{|c|c|c|c|c|c|c|c|c|}
\hline & B & S.E. & Wald & $\mathrm{df}$ & Sig. & Odds Ratio & \multicolumn{2}{|c|}{$95 \%$ C.I. } \\
\hline & & & & & & & Lower & Upper \\
\hline School Department & & & 17.99 & 2 & .000 & & & \\
\hline Law department & 0.71 & 0.23 & 9.36 & 1 & .002 & 2.04 & 1.292 & 3.217 \\
\hline Medicine department & 0.89 & 0.22 & 16.82 & 1 & .000 & 2.44 & 1.594 & 3.745 \\
\hline Constant & -0.68 & 0.16 & 17.74 & 1 & .000 & 0.50 & & \\
\hline
\end{tabular}

Note: .03 (Hosmer \&Lemeshow), .04 (Cox \& Snell), .05 (Nagelkerke). Model $-2 L L=680.55, \chi 2(2, N=506)$ $=18.62, p<.001$.

\subsection{School Department and Awareness of Legal Rights on SM}

To understand the relations between school department and awareness of legal rights on SM, respondents from three different school departments (Law, Medicine and Psychology) were asked with "Do you know your legal rights which you can impose, if you subject to a harassment on SM? The chi-square test indicated that the difference in departments was significant Pearson $\square \square 2(2, \mathrm{~N}=505)$ $=77.91, p<.001$. The frequencies of replies to this question are shown in contingency Table 10.

Direct logistic regression was performed to assess the impact of the school department and the likelihood that participants would report if they knew their legal rights which they could impose when subjected to a harassment on SM. In the analysis, as a dependent variable $260(51.5 \%)$ "yes" and 245 $(48.5 \%)$ "no" responses were used.

The model composed of one dependent variable "Do you know your legal rights which you can impose if you subject to a harassment on SM?" (no=0, yes=1) and an independent categorical variable school department ( $\mathrm{Law}=0$, Medicine $=1$, Psychology $=2$ ) coded with dummy variables with last level as being the reference.

\section{DISCUSSION}

In this study, the relations between gender and knowledge, attitudes, and behaviors of university students regarding the harassment on SM were investigated. University students used SM mostly for sharing with friends and for pleasure/fun purposes. Females were nearly 2.5 times more likely to use SM for sharing with friends than males. On the other hand, males were more likely to use SM for meeting with new people and for having boyfriend/girlfriend than females. A study by Mazman \& Usluel, 2011, similar gender differences to this study among Facebook users were found; females used significantly more frequently than males for maintaining existing relationships (sharing with friends), whereas males used significantly more frequently than females for making new relationships.

In this study, $47.5 \%$ ( $N=271)$ of the 507 respondents indicated that they were subjected to a sexual expression on SM while females $(52.2 \%)$ found nearly 2 times more likely to be subjected than males (38.2\%) did, $\square \square(1, \mathrm{~N}=507)=8.32, p<.001$. Montiel et al., 2016, found that $39.5 \%$ of the online victimizations were sexual, 53.4\% were non-sexual whereas $31.0 \%$ of youth reported in both domains. Twenty-five percent of young people across Denmark, Hungary and UK were being targeted by, and systematically excluded from, a group or community with the use of sexual content that humiliated, upset or discriminated against them (Project de SHAME, 2017). Our study found somewhat higher percentages than the others, nevertheless, it is noticeable from all studies that between $25 \%-50 \%$ of the SM users were faced with a sort of sexual expression on SM.

When the familiarity with the harasser on SM was asked, $89.0 \%(N=219)$ of the cases were defined as an unknown person among harassed students. The least frequent cases were girl/boy friend or spouse (1.6\%) and family member (2.0\%). Females were 3.5 times more likely to be harassed by an unknown person on SM than males. In a study by Smith et al., 2008, it was reported that $20.7 \%$ of the respondents did not know who cyber bullied them. Further in another study by Turan et al., 2011, it was reported that $79.3 \%$ of the respondents stated that the perpetrator was unknown. A survey by Jones et al., 2012 showed that harassment incidents in 2010 were more likely to come from a school friend or acquaintance and occur on SM. Hinduja and Patchin, 2008, found that $69 \%$ of victims did not know their harasser in person. These compatible findings indicate that anonymity contributes to SM harassment, since perpetrators may feel less personal responsibility and have more courage and power when their identity can be masked. 
When questioning the type of the harassment on SM, 52.7\% of the respondents had experienced any type of the harassment and this percentage was higher among females $(72.7 \%)$ than males $(27.3 \%)$. Among females, the most frequent answer was stalking (52.6\%) and sexual harassment $(44.8 \%)$ and the least frequent one was physical menace (4.6\%), whereas among males the most frequent answer was mock or curse (61.6\%) and the least frequent one was sexual harassment $(19.2 \%)$. There was a significant difference between the genders; females were more likely to face with sexual harassment on SM than males whilst males were more likely to face with mock or curse and physical menace than females on SM. Bossler et al., 2012 found that of the 434 cases, 35.3\% had experienced some form of online harassment within the past 12 months, and within a young sample being female is related with higher levels of online harassment victimization. Smith et al., 2008, indicated that girls were more likely to be cyber victims. Mesch, 2009 found that having an active profile on SM and being female emerge as higher risk factor for being cyber bullied. Montiel et al., 2016, found that $61 \%$ of adolescents reported online victimization in one-year period, $65 \%$ being female and $56 \%$ being male with significant difference. Study by Finn, 2004, revealed that 10\%-15\% of students received repeated e-mail or instant messages that "threatened, insulted or harassed" and more than half of the students received unwanted pornography. In a study by Kowalski \& Limber, 2007, students among 6th-8th graders, girls were being over-represented among victims. Patchin and Hinduja, 2006, stated that although some of the harassment might be characterized as trivial, more than $20 \%$ reported being threatened by others. In short, most of the studies up to date are supportive of this study in terms of females being more likely to be harassed on SM especially in the form of unwanted sexual harassment. In addition, as the years go by increase on SM harassments victimization observed due to more students having accounts and profiles on various SM platforms.

When questioning participants opinion on why they had faced with SM harassment, among harassed, they mostly thought it was due to their gender or sexual harassment purposes (58.9\%) and rarely due to race $(12.4 \%)$. Females mostly thought that it was due to their gender or sexual harassment purposes (70.5\%), whereas males thought it was mostly due to political opinion (55.9\%)..Females had a higher mean than males in online potential harassment acts of misogyny, request for company and sexual favors in a study by Biber et al., 2002. Majority of students, 58.7\% received unwanted pornography, which could be considered harassment reported in a study by Finn, 2004. As expected, especially here in Turkey, females mostly reported to be harassed on SM due to their gender or sexual harassment whereas males reported due to political reasons.

Participants feltanger (76.7\%) the most and had pleasure $(2.1 \%)$ the least when they experienced a SM harassment. Both females and males felt anger $(81.3 \%$ and $64.6 \%)$ the most; and none of the females had a pleasure, whereas none of the males felt guilt. Females $(81.3 \%$ and $25.8 \%)$ were more likely to feel anger and be ashamed than males; whilst males $(48.1 \%$ and $6.9 \%)$ were more likely to feel indifference and have pleasure than females. In another study conducted in Turkey by Turan et al., 2011, similar findings observed as $82.0 \%$ of females and $78.8 \%$ of males were angry; males were more likely to be excited than females; females were more likely to experience fear and embarrassment. Most studies up to date are in line with the findings herein; victims mostly feel anger and there is gender difference in feeling embarrassment and having excitement.

This study showed that there were significant correlations between ever being subjected to any sexual expression on SM and gender, time spent on SM, usage purposes of sharing with friends, meeting new people and expressing oneself. Correlated attitudes helped to form a regression model that could correctly classify $62.9 \%$ of cases to distinguish between participants who reported and did not report themselves ever having any sexual expression on SM. In a study by Bossler et al., 2012, hours spent online and being female were positively correlate with online harassment victimization. Also, Mesch, 2009 , with his logistic regression analysis found that odds of online victimization are higher for girls than boys, having a profile on a SM site, watching YouTube and participating in chat rooms were conductive to higher risk of online bullying. These specific examples and other cited studies along with this study support that gender, time spent on SM and usage of SM platforms for expressing oneself are predictive of sexual expression confrontation on SM.

In this study the difference between three different school departments attitudes towards SM were also investigated. Nearly half of the students defended freedom of expression that SM provides despite potential insult or harassment. Students of Law department and Medicine department were more likely to defend freedom of expression that SM provides despite potential insult or harassment than Psychology department. 
In addition, nearly half of the students knew their legal rights which they could impose if they subjected to a harassment on SM. As expected, students of Law department were nearly more likely to know their legal rights on SM than Psychology department and students of Psychology department were more likely to know their legal rights on SM than Medicine department.

The university students' reactions when they were subjected to a harassment on SM were also questioned. Among harassed, more than half either "blocked the harasser on SM (61.9\%)" or "did not mind, reply or change his/her behaviors (51.4\%)". This may indicate that most of the students prefer to isolate and ignore the harasser. On the other hand, less than five percent "took legal actions" or "obeyed to harasser worrying that their relatives or friends could learn". This shows that the students might not know their legal rights through, concerned about taking legal actions due to social pressure when deciphered or blocking/ignoring could be an adequate action to get around the harasser. Smith et al., 2008, found that pupils recommended blocking/avoiding messages, and telling someone, as the best coping strategies; but many cyber-victims had told nobody about it.

Only $1.2 \%$ of the respondents reported that they were in need of psychological treatment due to SM harassment and there were no significant gender differences. The previous studies show that being a cyberbully victim might pose a treat for the development of psychological problems on youth (Ybarra et al., 2004; Erdur-Baker \& Tanrikulu, 2010).

Almost two thirds of the respondents reported that they knew where to notify the harasser. Among them, for more than $90 \%$ office of public prosecutor was the preferred authority and nearly half had chosen SM complaint platform, while only one forth indicated police station. There were no gender differences among the answers.

\section{CONCLUSiON}

This study intended to explore Turkish university students from Law, Medicine and Psychology departments knowledge, attitudes and behaviors regarding the harassment on SM. The focus was given to relationship between genders and the knowledge, attitudes and behaviors and various attitudes and demographic variables that might help educators to predict university students ever being subjected to any sexual expression on SM.

In this study, highlighted findings can be summarized as;

- Females used SM to maintain contact with current friends and as a contact to friends whilstmales used it to flirt and make new friends.

- Nearly half of the respondents indicated that they were subjected to a sexual expression on SM while females found nearly 2 times more likely to be subjected than males did.

- Respondents indicated that they were mostly harassed on SM by an unknown persona and the least frequent cases were by girl/boyfriends or spouse and family members. Females were more likely to be harassed by an unknown person on SM than males.

- Nearly half of the respondents indicated that they had experienced any type of the harassment and this percentage was higher among females. Among females, the most frequent answer was stalking and sexual harassment, whereas among males the most frequent answer was mock or curse.

- Among harassed, they mostly thought it was due to their gender or for sexual harassment purposes. Females mostly thought that it was due to their gender or sexual harassment purposes, whereas males thought it was mostly due to political opinion.

Our research has some limitations as relying only on self-report measures to assess cyber bullying harassment. Some adolescents may over- orunder-report their harassment .This study is based on a cross-sectional design meaning that the data gathered at only on one time point from the university students.

In conclusion, without any regulatory corrective actions SM harassment to youth is a serious problem. Studies like we did which provide attitudinal and behavioral acts (properties) and knowledge of the SM users as university students based on their perceptions could help to support policies and practical solutions for universities, parents and other authorities. 
Technology develops faster than the legislative rules and law. These must be strengthened to address new challenges that new technologies pose.

\section{REFERENCES}

[1] Montiel, I., Carbonell, E., Pereda, N. (2016). Multiple online victimization of Spanish adolescents: Results from a community sample. Child Abuse \& Neglect 52, 123-134.

[2] Bossler, A.M., Holt, T.J., May, D.C. (2012). Predicting Online Harassment Victimization Among a Juvenile Population. Youth \& Society 44(4) 500-523.

[3] Project deSHAME. (2017). Digital Exploitation and Sexual Harassment Among Minors in Europe. A cross-country report.Childnet (UK), Kek Vonal (Hungary), Save the Children (Denmark) and UCLan (UK).

[4] Mazman, S.G., Usluel, Y.K. (2011). Gender Differences In Using Social Networks. TOJET: The Turkish Online Journal of Educational Technology - Volume 10, Issue 2.

[5] Smith, P.K., Mahdavi, J., Carvalho, M., Fisher, S., Russell, S., Tippett, N. (2008). Cyberbullying: its nature and impact in secondary school pupils. Journal of Child Psychology and Psychiatry 49:4, pp 376385.

[6] Turan, N., Polat, O., Karapirli, M., Uysal, C., Turan, S.G., Tippett, N. (2011). The new violence type of the era: Cyber bullying among university students Violence among university students. Neurology, psychiatry and Brain 17, $21-26$.

[7] Ybarra, M.L. (2004). Linkages between Depressive Symptomatology and Internet Harassment among Young Regular Internet Users. Cyber Psychology \& Behaviour Volume 7, Number 2, 247-257.

[8] Erdur-Baker, O. and Tanrikulu, A. (2010). Psychological consequences of cyber bullying experiences among Turkish secondary school children. Procedia Social and Behavioral Sciences 2, 2771-2776.

[9] Kowalski, R. M. and Limber S.P. (2007). Electronic Bullying Among Middle School Students. Journal of Adolescent Health 41, S22-S30.

[10] Hinduja, S. and Patchin,J.W. (2008). Cyberbullying: An Exploratory Analysis of Factors Related to Offending and Victimization. Deviant Behavior 29:2, 129-156.

[11] Patchin, J.W. and Hinduja, S. (2006). Bullies Move Beyond the Schoolyard: A Preliminary Look at Cyberbullying. Youth Violence and Juvenile Justice, 4: 148-169.

[12] Mesch, G.S. (2009). Parental Mediation, Online Activities, and Cyberbullying. Cyber Psychology \& Behaviour Volume 12, Number 4, 387-393.

[13] Sengupta, A. and Chaudhuri, A. (2011). Are social networking sites a source of online harassment for teens? Evidence from survey data. Children and Youth Services Review 33, 284-290.

[14] Biber, J., Doverspike, D., Baznik, D., Cober, A., Ritter, B.A. (2002). Sexual Harassment in Online Communications: Effects of Gender and Discourse Medium. Cyber Psychology \& Behaviour Volume 5, Number, 33-42.

[15] Finn, J. (2004). A Survey of Online Harassment at a University Campus. Journal Of Interpersonal Violence Volume 19, No. 4, 468-483.

[16] Jones, L.M., Mitchell, K.J., Finkelhor, D. (2013). Online Harassment in Context: Trends From Three Youth Internet Safety Surveys (2000, 2005, 2010). Psychology of Violence, Vol. 3, No. 1, 53-69.

[17] XTRlarge (2017). https://www.xtrlarge.com/2017/07/20/sosyal-medya-cevrimici-taciz/Accessed on 10.03.2020.

[18] Turkstat (2021). Population Statistics Report for the year 2020. https://data.tuik.gov.tr/Bulten/Index? $\mathrm{p}=$ The-Results-of-Address-Based-Population-Registration-System-2020-37210Accessed on 17.07.2021.

[19] We are Social - Digital Around Global (2021) https://wearesocial.com/digital-2021

[20] We are Social - Digital in Turkey (2021) https://datareportal.com/reports/digital-2021-turkey?rq=turkey

Citation: Oğuz POLAT, Zeynep REVA. "Knowledge, Attitudes and Behaviors of University Students Regarding the Harassment on Social Media in Turkey" International Journal of Humanities Social Sciences and Education (IJHSSE), vol 8, no. 10, 2021, pp. 42-52. doi: https://doi.org/10.20431/2349-0381.0810006.

Copyright: (1) 2021 Authors. This is an open-access article distributed under the terms of the Creative Commons Attribution License, which permits unrestricted use, distribution, and reproduction in any medium, provided the original author and source are credited. 